\title{
RETÓRICA POLÍTICA EN LOS DEBATES TELEVISADOS: CASO DE ZAPATERO-RAJOY (2008)
}

\author{
Juan Cantavella Blasco \\ (Universidad CEU San Pablo, Madrid-España) \\ jcantavella@ceu.es \\ César Mejía Chiang \\ (Universidad de San Martín de Porres, Lima-Perú) \\ cmejia@comunicaciones.usmp.edu.pe ${ }^{1}$
}

\begin{abstract}
Resumen: Conviene atender a las incitaciones retóricas que contiene el lenguaje político (que con frecuencia se proyecta sobre la persuasión periodística) y, en esa línea, hemos elegido el debate electoral entre Rodríguez Zapatero y Rajoy para analizar los aspectos más sobresalientes. Aquí se atiende sobre todo a los argumentos y a las falacias, pero también a otros aspectos peculiares de sus discursos.
\end{abstract}

Palabras clave: Política, Retórica, Lenguaje político, Lenguaje periodístico, Persuasión.

Abstract: It is necessary to pay attention to rhetorical incitements in the political language (which is frequently shown through journalistic persuasion) and, along these lines, we have chosen the electoral debate between Rodriguez Zapatero and Rajoy in order to analyze the most important aspects. Here, above all, we pay attention to the arguments and fallacies of their speeches, but also to some other specific aspects.

Keywords: Politics, Rethoric, Political language, Journalistic language, Persuasion.

\section{INTRODUCCIÓN}

s sabido que la actividad forense estuvo en la base de la retórica, que es "el estudio de las propiedades de los discursos" (Dubois, 1979: 536), de donde derivó hacia las contribuciones que el discurso recibe en orden a expresar las ideas y los sentimientos de una manera bella y eficaz. Pero eso fue en los comienzos, porque superado aquel momento inicial fue tomando otros derroteros, siempre ricos y provechosos (menos cuando se detuvo en minucias improductivas). En nuestros días, donde encuentra mayor arraigo su aplicación es en dos campos muy asentados en nuestra sociedad, como es la literatura y la política (y entre medias, el periodismo). En el primero lo que prima es la búsqueda

\footnotetext{
${ }^{1}$ Coautores: Luis Antonio Curiel Calleja (Universidad CEU San Pablo, Madrid-España), charecu@hotmail. com; Rachel Bullough (Universidad CEU San Pablo, Madrid-España), rbulloug@ceu.es; Esteban Pittaro (Universidad Austral, Buenos Aires-Argentina), pittaro@gmail.com; Begoña Morales BlancoSieger (Universidad CEU San Pablo, Madrid-España). bmorales@indra.es.
} 
Retórica política en los debates televisados:

caso de Zapatero-Rajoy (2008)

de la belleza, mientras que en el segundo es la eficacia (y podríamos decir que en el articulismo periodístico tanto una como otra). En cualquier caso se aprecia una recurrencia muy notable a sus potencialidades y eso lleva a que la retórica no haya quedado sepultada bajo la pátina del olvido, sino más bien a que reviva con ansia y aun emprenda direcciones nuevas y prometedoras.

En los últimos tiempos vemos cómo ha tomado impulso esta última tendencia: la concepción de la retórica como teoría del discurso persuasivo (que tiene en la argumentación su eje y razón de ser) habría determinado el renacimiento de la disciplina a mediados de este siglo (Mortara, 1991: 57). ¿Tienen interés para los comunicadores las indicaciones que se desprenden del enfoque actual de la argumentación? Es evidente que mucha, como se pone de relieve por el resurgimiento que se aprecia en las últimas décadas. Su aplicación al campo de la opinión periodística se puede seguir a través de trabajos que han sabido extraer las mejores lecciones de aquellas ideas, lo que resulta muy útil para el análisis de los textos que se presentan en los medios de comunicación, donde argumentos y sofismas encuentran su lugar, en ocasiones muy revueltos.

Determinados periodistas y los escritos que emanan de ellos guardan excesivas semejanzas (o dependencia) de los políticos y de sus discursos (de sus intervenciones y de la forma de comunicar en declaraciones o encuentros informales). Las maneras de expresarse de estos son calcadas y reiteradas por los informadores que les escuchan y de esa forma pasan sin censura y sin crítica al torrente del habla popular, aun rodeados del halo de distinción que siempre acompaña a una fuente de tanto prestigio. Por eso es importante para los periodistas atender a los rasgos distintivos del lenguaje de los políticos, pues resulta útil conocerlo y detectarlo; después, desde el conocimiento, es conveniente mantener distancias para no copiarlo ni imitarlo, porque los aspectos negativos pueden contaminar nuestros textos $y$, a través nuestro, el de quienes nos leen o escuchan, muchas veces con respeto y admiración.

\section{OBJETIVOS Y METODOLOGÍA}

Esta investigación busca identificar y evaluar los recursos retóricos empleados por los entonces candidatos a la Presidencia de Gobierno, José Luis Rodríguez Zapatero, por el Partido Socialista Obrero Español; y Mariano Rajoy Brey, por el Partido Popular. Para lograr tal cometido, se ha tenido acceso a las transcripciones oficiales y completas de las intervenciones de los mencionados dirigentes en las dos emisiones televisivas que tuvieron lugar los días 25 de febrero y 3 de marzo de 2008. Gracias a este material, se ha podido observar y analizar con detalle la calidad del discurso y el vocabulario vertido por dichos líderes políticos. 
Juan Cantavella Blasco

\section{HIPÓTESIS DE TRABAJO}

Esperados con mucha expectación (similar al que despertó su antecesor en $1993^{2}$ ) los dos debates mantuvieron muchas similitudes en organización y temática ${ }^{3}$. Sin embargo, tras un examen profundo, no se puede afirmar lo mismo en el desarrollo de la exposición discursiva, es decir, en materia de expresividad y tono; empleo de vocabulario; énfasis en palabras generalmente emotivas y trascendentes en determinados contextos; así como en la configuración de retóricas abocadas a atacar/desvalorar/ironizar/deslegitimar las apreciaciones y opiniones del contendiente en diferentes puntos del debate.

\section{FALACIAS EN LA ARGUMENTACIÓN}

Dentro del análisis retórico referido al discurso político, la facultad de la argumentación ha sido confundida, amalgamada y erróneamente emparentada con la persuasión falaz, la propaganda y la manipulación. Tal fenómeno ha sido inevitable, sea por la naturaleza misma del enrarecido ambiente político o por la tendencia casi inexorable (mostrada por buena parte de los candidatos que en el mundo han sido) hacia la demagogia. En todo caso, es necesario realizar un deslinde conceptual entre la auténtica exposición de argumentos y las falacias que se lanzan para confundir al adversario. En primer lugar, las expresiones y mensajes persuasivos tratan de mostrar una verdad, sin tomar en consideración el grado de relativismo que suele acompañarla. Sin embargo, eso no significa que tengan un carácter irracional. De acuerdo con Berrio (1983: 210), esto último evita una coacción explícita y la aplicación de la "seducción de las palabras" que pueda producirse.

La frontera entre la razón y la seducción es borrosa. Por ese motivo, la persuasión suele ser hermanada con la propaganda, porque la primera es fuente primordial de la segunda. Tras las experiencias totalitarias en las primeras décadas del siglo pasado, quedó claro que la propaganda no sólo busca elaborar un discurso grato y cautivante, sino también la aceptación por parte del público de una tesis política o ideológica a despecho de las razones de peso en que deben sustentarse. Para ello, depende más de la teatralidad y aspectos extralingüísticos que de la propia racionalidad del mensaje.

Por ese motivo, Carmen Herrero (1996: 60) considera la propaganda como un tipo de comunicación exclusivamente dependiente de la fe, los sentimientos, las

\footnotetext{
${ }^{2}$ El primer debate televisado fue protagonizado por el entonces presidente de Gobierno Felipe González y José María Aznar. Se suele afirmar que la victoria del dirigente socialista se debió precisamente a su adecuado desenvolvimiento ante las cámaras frente a un novato líder popular.

${ }^{3}$ Los dos debates estuvieron provistos de dos partes: la primera encerraba temas de debate general ("economía y empleo", "política social", "política exterior", "seguridad") y la segunda ofrecía la oportunidad de exponer perspectivas ("política institucional", "retos del futuro"). Con la aparente finalidad de ofrecer una paridad de género, el moderador de la sesión de febrero fue un varón (Manuel Campo Vidal), mientras que la de marzo recayó en una mujer (Olga Viza).
} 
Retórica política en los debates televisados:

caso de Zapatero-Rajoy (2008)

alegorías, los estereotipos y otras expresiones de irracionalidad. En esencia, es una "crítica emocional" no objetiva, sino repetitiva y cuasimesiánica. Haciendo un distingo con los fines de la educación, Herrero concluye que no forma criterios independientes, sino que proporciona criterios prefabricados: más que un proceso lento de desarrollo, el propagandista persigue resultados rápidos y busca formar una mentalidad cerrada que gire alrededor a una ideología determinada.

Por su parte, la manipulación se diferencia de la propaganda por ser una versión brutal, efectista y no ética de esta. Ideas y premisas -sabiéndose de antemano su falsedad- son expuestas frente a las audiencias con una retórica verosímil y legitimadora. La exposición sistemática de una mentira como una verdad incuestionable ha sido una rutina favorita bajo los gobiernos dictatoriales.

A diferencia de las dos modalidades mencionadas, la auténtica argumentación plantea un discurso avalado por hechos y afirmaciones racionales. No obstante, la realidad social hace voluble (y a veces aparente o inexistente) la verosimilitud de una argumentación. Asumir que la argumentación (sobre todo en el ámbito político) es un canal libre de todo prejuicio o tendencia a la manipulación es pecar de ingenuidad.

Desde la época de Aristóteles, se han reconocido varios errores en la praxis argumentativa. El número de incoherencias y falacias que pueda contener el discurso revela, lamentablemente, la nimia altura que puede alcanzar, a poco que nos descuidemos en cuestiones de veracidad y confiabilidad. De argumentos y de falacias, pero sobre todo de éstas, hablamos a continuación.

\section{ANÁLISIS DE LOS DEBATES TELEVISADOS: FALACIAS MÁS RECURRENTES}

En este bloque haremos un análisis de los principales argumentos empleados por José Luis Rodríguez Zapatero y Mariano Rajoy en los dos debates electorales de los que nos estamos ocupando. Los temas tratados son similares en ambos casos, aunque no sucede lo mismo con la forma. Entre los argumentos empleados por uno y otro nos encontramos con los siguientes.

5.1. Argumentum ad populum o apelación a la multitudEste recurso invoca los intereses del auditorio, empleando frases demagógicas, cómodas y caprichosas. Obviamente, defiende y se escuda en "verdades" que parecen ser de "sentido común", pero no son necesariamente ciertas. Es el razonamiento elaborado apelando a la emoción. Cuando una persona, un auditorio o un público lector reciben un mensaje con altas dosis de exaltación es posible que acepten seudorrazonamientos que no buscan otra cosa que defender o atacar algo con un lenguaje altamente emotivo.

¿A ustedes qué les parece? ¿Estamos mejor que hace cuatro años? Depende de a quién le hagamos la pregunta $(\mathrm{D} 1-\mathrm{R})^{4}$.

\footnotetext{
${ }^{4}$ Las abreviaturas D1 y D2 corresponden a "primer debate" y "segundo debate" respectivamente. Del mismo modo, la Z y la R hacen referencia a Rodríguez Zapatero y Mariano Rajoy.
} 
Con estas preguntas retóricas comenzó Mariano Rajoy sus intervenciones en los debates. En la primera de las tres oraciones, Rajoy interpeló a los públicos utilizando el "ustedes". Sin embargo, en la segunda pregunta se involucró más y se hace uno con el público, utilizando el verbo en primera persona del plural. En la tercera oración, la respuesta a las dos preguntas anteriores incide en la utilización de la primera persona en plural. Si bien la respuesta fue una conclusión perfectamente aceptable (pues la respuesta variará según la persona a la que se le pregunte) la falacia apeló al público con las preguntas retóricas y la respuesta obvia, buscando la identificación con el candidato.

La disyuntiva en las próximas elecciones es: diálogo o confrontación; aquellos que buscamos soluciones o quienes fabrican problemas, aquellos que desde el poder servimos a los ciudadanos y aquellos que han intentado utilizar a los ciudadanos para llegar al poder (D1-Z).

José Luis Rodríguez Zapatero buscó, mediante esta sucesión de comparaciones, la instalación de una disyuntiva, probablemente inexistente, a partir de la apelación a supuestos deseos de los ciudadanos. Difícilmente puede haber ciudadanos que busquen votar a un candidato que fabrica problemas, y el presidente, ante este supuesto atributo del Partido Popular, se identificó entre los que buscan soluciones. Pretendió, mediante este argumento, polarizar la dirección del voto aludiendo de manera intencionada a los deseos propios de cualquier ciudadano democrático.

Yo voy a hablar de lo que afecta fundamentalmente a los españoles, y voy a hablar de cómo viven los españoles, que no viven como usted cree que viven los españoles (D2-R).

En esta instancia del segundo debate, Mariano Rajoy buscó hacerse portavoz de los españoles. Pese a que apeló a las masas de manera indirecta (ya que el destinatario real de su formulación fue Rodríguez Zapatero) se puede afirmar que fue un argumento ad populum, pues se refiere a la supuesta situación de los ciudadanos. La carencia argumental de este tipo de falacias se ilustró a partir de la utilización del mismo contenido por el otro candidato, como muestra el siguiente caso:

No le ha importado este tema. Pero yo quiero hablar de los problemas de los ciudadanos... (D2-Z).

Nuevamente el candidato, en este caso el líder socialista, se refirió a "los problemas de los ciudadanos", buscando hacerse su portavoz. Es una llamada a la emotividad, un intento de involucrarse con las preocupaciones ciudadanas, que más allá de que en la posterior enumeración de los inconvenientes se acierte, tuvo como fin manifestar que la solución de los problemas se identificaba con la figura del candidato.

\subsection{Argumentum ad baculum o apelación al poder}

Constituye una falacia de primer orden, puesto que la razón que se esgrime no es otra que o bien la amenaza, más o menos directa, más o menos oculta, o 
Retórica política en los debates televisados: caso de Zapatero-Rajoy (2008)

bien el establecimiento de unas consecuencias no deseables que se padecerían si no se sigue la norma propuesta, penden sobre las cabezas de los electores. Este tipo de argumentación es propio de un pensamiento dogmático, que no sólo está convencido de su razón única y excluyente, sino que además no está dispuesto a aceptar que existan otras opciones que la contraríen, por lo que acudirá a cualquier acto de fuerza o coacción. Está muy relacionado con el argumento de apelación a la autoridad 5 , pero las frases se apoyan en la "experiencia", la "carrera pública" y el "poder político" (sobre todo Zapatero) que el orador suele (con poca humildad) mostrar y exhibir frente a su contrincante. $Y$ eso es percibido en ocasiones como una amenaza.

La ausencia de apelaciones a autoridades en ambos debates, por parte de los candidatos, sugiere varias interpretaciones que no son objeto de este trabajo dilucidar. Sin embargo, pese a que ninguno citó a ninguna persona, sí se observaron invocaciones a dos realidades, una concreta y otra abstracta (pero no por ese menos real), que suponen autoridad: "Europa" y la "Verdad". Puede resultar audaz categorizar ambas referencias como apelaciones a la autoridad, pero lo cierto es que los candidatos se refirieron a ellas buscando consolidar la fuerza de sus argumentos.

La Comisión Europea acaba de pronosticar que España será el país que más crezca en 2008. Y el crecimiento para nosotros supone distribuir la riqueza (D1-Z).

Hace poco más de un mes uno de los principales periódicos europeos se preguntaba sobre España: ¿qué se puede esperar de un país en el que sus habitantes no se ponen de acuerdo sobre cuántas naciones son? (D1-R).

La ausencia de autoridades personificadas durante el primer debate, y la discrepancia de opiniones impulsó el llamamiento a una autoridad, tampoco personificada: la palabra "Verdad" y sus accidentes (especialmente en su expresión adverbial, "verdaderamente") aparecieron siete veces mencionadas en el primer debate, y en todas las ocasiones por el candidato del PP.

Usted, sobre todo, ha mentido, ha engañado, ha faltado a la verdad, pero en infinidad de ocasiones. Se lo he demostrado. Ha dicho una cosa y la contraria muchísimas veces (D1-R).

En el segundo debate, el presidente del Gobierno apeló a la "Verdad" (y a sus variantes) en diez ocasiones, mientras que el líder del Partido Popular lo hizo en catorce. La falta de referencias subjetivas hizo que la apelación a la autoridad

\footnotetext{
${ }^{5}$ Se produce cuando el orador emplea una frase o las ideas de un connotado pensar o personaje prominente a fin de avalar sus propios argumentos. Generalmente se los usa de forma descontextualizada y con fines simplemente de prestigio. En la misma línea nos encontramos con el hecho de que, en las campañas electorales, los partidos políticos en liza se afanan por encontrar todo tipo de personajes de la vida pública, intelectuales o artistas, deportistas o científicos, para que con su presencia respalden las posiciones políticas e ideológicas que cada grupo representa. Esto forma parte ya de la propaganda inevitable y de muchas disputas entre partidos que necesitan verse respaldados por ciertas "autoridades".
} 
más recurrida fuese, justamente, la más objetiva. La "Verdad", que incluso buscó ser demostrada por Rodríguez Zapatero con un libro, o por ambos candidatos a lo largo de los dos debates mediante gráficos, fue la máxima autoridad.

\subsection{Petitio principii}

La "petición de principio" es una falacia en la argumentación que busca elaborar un discurso, con tesis y conclusiones que solamente son lógicas en apariencia 6 . Su incoherencia radica en que defiende algo "como verdad antes de haberlo demostrado, es decir, cuando se llega a la conclusión precipitada sobre algo que está en proceso de investigación o de demostración" (Santamaría y Casals, 2000: 209-227).

No hay duda de que este recurso se encuentra de forma abundante en los ataques a la administración del PSOE, así como en los calificativos negativos al líder de la oposición. Son "afirmaciones precipitadas" que resaltan notablemente, gracias a su considerable contenido de dramatismo y de absoluta certeza. Tal dúo desconcertante ayuda a crear diferentes ambientes durante el discurso, sea para alimentar una sensación "catastrofista", o "redentora", como para subrayar la ironía y la caricaturización del contrincante que construye el adversario.

Al analizar el contenido de los discursos e intervenciones de ambos personajes políticos, se han podido identificar cuatro subespecies pragmáticas dentro de los alcances falaces de la petitio principii, las cuales, muchas veces, se complementan entre sí:

1. Generalizaciones: Más que un ejercicio deductivo (método que parte de lo universal a lo particular), revela prejuicios y estereotipos que no tienen ningún sustento racional. Asimismo, es un signo de ignorancia o desprecio al contexto que envuelve un hecho o un tema en especial.

2. Exageraciones: Implica representar y describir una situación de forma hiperbólica y lejana de la realidad, con la finalidad de subrayar ciertos aspectos (dramáticos, íntimos, pasionales) que generalmente suelen ser superfluos y ajenos a la naturaleza del hecho en sí.

3. Ataques gratuitos: A diferencia de los argumentos ad hominem, no recurren a las alusiones personales, pero sí contribuyen a generar desaprobación y desconfianza hacia el receptor de tales críticas.

4. Promesas utópicas: Es, probablemente, uno de los recursos más estimados y usados por los políticos, presente en diferentes épocas y sistemas a lo largo de la historia universal. A diferencia de las exageraciones, siempre

\footnotetext{
${ }^{6}$ Por ese motivo, la petitio principii está intrínsecamente ligada a la intencionalidad de otras modalidades falaces, tales como la de "falsa causalidad", que establece relaciones de causalidad falsas y erróneas; la de "círculo vicioso", que para probar algo se emplea en la argumentación lo mismo que se pretende probar, sin avanzar en la demostración; y de "falsa analogía", que abusa de las semejanzas entre dos elementos o casos (Herrero, 1996: 78-79).
} 
Retórica política en los debates televisados: caso de Zapatero-Rajoy (2008)

busca proponer un futuro y un destino próspero a la audiencia, sin considerar las grandes dificultades (incluso la imposibilidad) para concretar tal finalidad.

En el primer debate se observó una considerable diferencia en el empleo de esta falacia en uno y otro candidato (cuatro veces en el mensaje de Rajoy frente a las llamativas once ocasiones de Rodríguez Zapatero). Esto no sorprende si se tiene en cuenta que el discurso de Zapatero tenía, desde el primer momento, un cariz optimista y alejado de los problemas. Con un mensaje ameno y con ciertos aires de despreocupación, quería evitar los embates y críticas que tenía preparados Mariano Rajoy, a fin de desmoronar sus propuestas.

En ese sentido, el líder del Partido Popular se abocó a lanzar una retahíla de críticas gratuitas, generalmente dirigidas hacia la cuestionable política de seguridad de Zapatero y su concepción "fragmentarista", la que propicia su permisibilidad hacia lo que propugnan algunas comunidades autónomas. Ambos temas estuvieron fuertemente presentes, desde la apertura de su discurso:

Se ha centrado en dos cosas y las dos las ha hecho mal: la estructura de España y los tratos con ETA. Ha querido modificar por su cuenta el modelo de Estado y ha querido negociar con los terroristas por su cuenta. Ambas operaciones le han salido mal (D1-R).

Sobre el caso de la supuesta negociación con ETA, Rajoy procuró no centrarse exclusivamente en los hechos y consecuencias de los actos terroristas, sino en la palpable presencia de ese grupo en la política nacional, lo que supone a su juicio el resquebrajamiento de la unidad de España:

Negoció con ETA, rompió el pacto, les dio esperanza. Nos dijo que querían retirarse, que mostraban una voluntad inequívoca, que usted había verificado. Que no iba a hablar de política. ¿Cuál es el resultado? ETA está en los ayuntamientos y el Parlamento con nuestro dinero. Vuelve la violencia callejera, han vuelto a matar, ha roto un gran acuerdo nacional... Y además usted dividió a la sociedad y se enfrentó a las víctimas (D1-R).

El empleo de las exageraciones suele tener cierto impacto, dependiendo de la paleta lingüística con que se trabaje, así como de los adjetivos pertinentes y "precisos" que se apliquen. Rajoy apostó por acusaciones contundentes durante la introducción:

Ningún gobernante ha sembrado en la historia de la democracia moderna tanta tensión y cizaña mientras hablaba de entendimiento, de talante y de convivencia. Ninguno ha transmitido a los españoles una sensación comparable de falta de rumbo, de improvisación y de vivir pendientes de las ocurrencias cotidianas (D1-R).

Pese a su aparente apacibilidad y su renuencia a una confrontación clara y directa, las intervenciones de Zapatero fueron las que más abusaron de las subespecies de la petitio principii, sobre todo las exageraciones en el aspecto económico, donde revelaron cierta "mitomanía optimista", ajena a la fuerte recesión 
(que denominó eufemísticamente "desaceleración") que de manera irremediable nos acecha en la actualidad:

La desaceleración no va a ser profunda ni prolongada: va a ser una desaceleración para la que España está más preparada que nadie, por la fortaleza de su sistema financiero y de sus cuentas públicas (D1-Z).

Hemos crecido más que los ocho grandes países industrializados y hemos creado más empleo que ellos. Ese balance nos da tranquilidad para asumir un proceso de desaceleración mundial que tenemos en estos momentos (D1-Z).

Dentro del debate social no se hicieron esperar las generalizaciones, que buscaban convocar el interés de los sectores jóvenes, específicamente en su emancipación económica e integración adecuada al sistema laboral. Cabe resaltar que Rodríguez Zapatero tiende a realizar comparaciones en detrimento a la gestión anterior de sus adversarios:

Hemos subido el salario mínimo al 30 por ciento, eso es política social. Hemos apoyado a los jóvenes para la vivienda en alquiler, con una renta de emancipación que va ayudar a 350.000 jóvenes. Ustedes, ni un euro para ayudar a los jóvenes en el alquiler (D1-Z).

Ese último detalle podría caracterizar la tendencia provocadora y mordaz (sutil, pero efectiva) del actual jefe de gobierno, fusionando los ataques gratuitos con el tono grandilocuente de la exageración. Tal construcción híbrida estuvo preferentemente dedicada a la labor política de Rajoy: algunas lindaban con el ataque ad hominem, otras denunciaban a mansalva la irresponsabilidad y cinismo del líder del PP, especialmente en el aspecto económico, a fin de devaluar las críticas de Rajoy al modelo financiero del PSOE:

El principal obstáculo ha sido una oposición que desde el primer día no aceptó el resultado electoral, que ha practicado el insulto personal (usted mismo, señor Rajoy), que es una barrera que no se puede traspasar en democracia. Que ha crispado, que ha enfrentado a ciudadanos de unas comunidades con otras [...] que no ha dado respaldo al Gobierno en ninguna de las grandes cuestiones de Estado (D1-Z).

¡Pero si usted no se ha preocupado por la economía en cuatro años! [...] Usted no se ha dedicado nada a la economía. Todo el mundo sabe a lo que usted se ha dedicado: a hacer oposición con lo único que no tenía que haberlo hecho, con ETA (D1-Z).

En las discusiones en torno a la política social, Rodríguez Zapatero amplió el objetivo de su ataque hacia todo el aparato ideológico de Rajoy, no sólo poniendo en duda su capacidad de gobierno, sino su carácter autoritario y poco proclive a la libertad ciudadana y al logro de un "Estado de bienestar":

Desde hace treinta años no han movido un dedo para que los españoles tengan más derechos, ni en la sanidad, ni en la educación, ni en las libertades individuales, ni en investigación biomédica. Si ustedes hubieran gobernado treinta años seguidos, lo que es evidente es que en España hubiera habido menos educación, menos sanidad, menos derechos, peores pensiones y, desde luego, seríamos un país menos libre y más intransigente (D1-Z). 
Retórica política en los debates televisados: caso de Zapatero-Rajoy (2008)

Rodríguez Zapatero concluyó su intervención lanzando una promesa utópica, combinándola sagazmente con la temeridad en las frases en primera persona ("estoy resuelto", "estoy decidido") y en la insistencia de su posibilidad de realización ("Está a nuestro alcance"). Estas repeticiones edulcoraron hábilmente las propuestas difíciles de concretar a corto plazo:

Estoy resuelto a que la igualdad de hombres y mujeres en derechos y en salarios haga compatible la vida familiar y el trabajo [...]. Estoy decidido a que España esté en la vanguardia de la lucha contra el cambio climático, en la calidad de la educación, en las infraestructuras. Está a nuestro alcance. Estoy decidido a que España esté siempre en el mundo defendiendo la paz, lejos de las guerras ilegales [...]. Todo esto es posible. Está a nuestro alcance (D1-Z).

Debido a los resultados obtenidos en la primera confrontación televisiva, el segundo debate obligó a Rajoy a remodelar su discurso, planteándolo mucho más explicativo (con mayores propuestas y alternativas de solución a los problemas de Estado) y menos incisivo en las críticas al inmediato pasado. Por ese motivo, la petitio principii aparece con una notable uniformidad en el mensaje de ambos líderes políticos (ocho ocasiones en Rajoy; siete en Rodríguez Zapatero). En ese sentido, Rajoy asimiló la forma híbrida de la acusación crítica con ribetes exagerados (empleada por su oponente en el debate anterior) recurriendo a ella a lo largo de temas y contextos tan disímiles como la economía, la política de seguridad y los "retos del futuro". Si bien aumentó la cantidad, las críticas fueron las mismas (negociación ilegal con ETA, carácter separatista de los estatutos de autonomía) pero sin redondear una inculpación más categórica:

Al que no le ha importado la economía es a usted, que además era el presidente del Gobierno, que ha preferido dedicarse a otras cosas como le he dicho antes: a negociar con ETA, a hacer cábalas sobre España que al final han terminado como han terminado... (D2-R).

Su idea de España no la conoce nadie. Usted abrió un proceso, actuó de aprendiz de brujo y abrió un modelo para que todo el mundo hiciese lo que estimase oportuno y conveniente sin saber a dónde iba [...]. Enfrentó a todas las comunidades autónomas entre sí, por el agua, por el patrimonio, por las inversiones, por la financiación... Dividió a los españoles (D2-R).

Como se puede comprobar, muchas de estas acusaciones excesivas y poco fundadas fueron leves, comparándolas con las de su contrincante. En otras palabras, no tuvieron el contenido mordaz y directo que supo imprimirle el líder del PSOE. Sin embargo, podemos hacer una excepción: "Lo que pasa es que usted (Zapatero) pierde perspectiva porque se ha ido muy, muy hacia el extremo y entonces nos ve en otro lugar" (D2-R), que denunciaba el progresivo desplazamiento del PSOE hacia (a su entender) un radicalismo de izquierdas.

Al darse cuenta de los resultados obtenidos en el primer debate, el discurso de Rodríguez Zapatero continuó en la misma línea, con una sutil diferencia: ahondó un poco más en los ataques a su opositor, a fin de transmitir mayor solidez y 
autoridad. Esto quedó demostrado en la discusión concerniente a la inmigración. Las acusaciones a la administración del PP (con referencias implícitas a Aznar) en esta materia lindaron con la mordacidad y la cruel ironía. Las figuras del "bonobús", la factura de "una noche de hotel" y la "rueda de bicicleta" llegan a ser peyorativas, pero tuvieron como función arrancar una sonrisa o comentarios sarcásticos a los telespectadores.

El pináculo de la estrategia agresiva de Rodríguez Zapatero se alcanzó en el debate sobre política exterior y seguridad. La intervención de España en Irak, durante la administración de Aznar, se convirtió en la "patata caliente" que le quemaba recibirla a Mariano Rajoy, quien se limitó a rebatir como pudo dichas acusaciones. Algo que fue aprovechado por el PSOE para aplicar duras frases interrogativas que rayaban en la inculpación:

¿Sigue apoyando la guerra de Irak? ¿Sigue apoyando la guerra de Irak? No, dígalo, dígalo. ¿Usted cree que fue una buena aventura? ¿Cree que fue una buena aventura? ¡Está defendiendo la guerra de Irak! (D2-Z).

En otro momento se inclinó por el lanzamiento de promesas utópicas, en mayor cantidad que en el debate anterior. Probablemente esto se debió a que el líder del PSOE era consciente de cautivar al electorado indeciso y juvenil, aplicando un discurso conciliador y que apostaba por un futuro prometedor:

Mi objetivo en la próxima legislatura es el pleno empleo. Mi primera acción será convocar a sindicatos y empresarios para firmar un gran acuerdo para toda la legislatura, con prioridades urgentes, para afrontar las consecuencias de la desaceleración que vive la economía mundial. Vamos a poner en marcha una batería de acciones para la reactivación económica, con sindicatos y empresarios (D2-Z).

Gran reto de política social para mí: la igualdad definitiva entre mujeres y hombres, con planes de empresa a empresa, para que se cumpla a rajatabla la regla de que a igual trabajo, igual salario. Y, como todos los trabajadores, mujeres y hombres, tienen igual derecho a hacer compatible su trabajo con la vida familiar, vamos a ampliar el derecho de paternidad y el derecho de maternidad (D2-Z).

\subsection{Carácter apelativo: frases negativas e interrogativas}

En discursos de esta naturaleza las frases negativas se convierten en un medio para que los interlocutores se crucen acusaciones sobre la base de la interpretación que hace el censor de los contenidos expresos o implícitos en la intervención del primero. Estas frases negativas son fáciles de identificar en las réplicas de los debates y tienen como objetivo desvalorizar la opinión del contrario. En el primer debate, Rajoy usó este tipo de frases 110 veces, frente a las 84 de Zapatero. Rajoy intentaba demostrar dos cosas con este empleo de frases negativas: por un lado, acusar a Zapatero de que mentía en sus logros y que no había hecho nada en estos cuatros años que ocupó el poder y, por otro lado, afirmar su propósito de buscar grandes mejoras a favor de los españoles, rechazando lo que él no realizaría (a modo de crítica a Zapatero). 
Retórica política en los debates televisados: caso de Zapatero-Rajoy (2008)

Pues, mire, yo no he dicho nunca que la Transición se hizo mal, y que España no estaba cuajada, eso lo ha dicho usted. Yo no he dado a entender a los nacionalistas que me proponía arrejuntar España, lo ha dicho usted. Yo no he dicho nunca que los vascos tuvieran el derecho a decidir, ni los extremeños, ni los murcianos, ha sido usted. Usted no tiene ninguna idea de la nación española (D1-R).

En el caso de Zapatero, el uso de frases negativas sirvió para acusar a Rajoy de sus actuaciones cuando estuvo en el Gobierno y como líder de la oposición durante los últimos cuatros años de gobierno socialista, así como para defender las políticas que como presidente ha llevado a cabo durante estos cuatro últimos años:

El principal obstáculo ha sido una oposición que desde el primer día no aceptó el resultado electoral, que ha practicado el insulto personal [...], que no ha dado respaldo al Gobierno en ninguna de las grandes cuestiones de Estado, que no ha dudado en utilizar el terrorismo con fines partidistas, que no ha dudado en utilizar el dolor de las víctimas (D1-Z).

Otro ejemplo especialmente significativo es el que se produce en un momento del primer debate. El uso de la frase negativa adquiere aquí un sentido pleno de refutación y de rechazo a las críticas recibidas. Es una sentencia rotunda por ambas partes:

No, no, señor Rajoy, no se lo acepto. Es una acusación muy grave, yo no he agredido a ninguna víctima del terrorismo (D1-Z).

Es igual que usted no me lo acepte, me trae completamente sin cuidado (D1-R).

En el segundo debate, Zapatero utilizó las frases negativas en 74 ocasiones, frente a las 134 de Rajoy. Una insistencia en el tono empleado en el primer debate, donde las frases negativas se emplearon para expresar rotundidad y criticar las diversas actuaciones políticas de ambos candidatos.

Usted en política de inmigración, no es que hayan hecho una política dialogada con empresarios y sindicatos, es que no han hecho absolutamente nada. No ha hecho absolutamente nada [...]. Usted no le ha dedicado un duro a la integración de la inmigración, usted no es consciente de este problema. No es consciente de los grandes problemas que le está generando a muchos ciudadanos españoles (D2-R).

No, no. Aquí está la pregunta. [...] Ni de los precios, ni de la economía ni de nada (D2-Z).

En el apartado de "política exterior y seguridad" del segundo debate, nos encontramos un diálogo tenso entre Rajoy y Zapatero. El tema se refiere a las negociaciones con ETA y es Rajoy quien acusa a Zapatero de mentiroso. Las respuestas de Zapatero son contundentes ("nunca jamás") e interrumpen varias veces el discurso de Rajoy para expresar con contundencia que no está de acuerdo con las afirmaciones que se hacen en su presencia. Es una negación que se repite hasta tres veces: 
-RAJOY: Usted mintió a los españoles cuando después de la T-4, dijo que no iba a hablar con ETA [...]. Usted le ha mentido a los españoles en todos los temas del terrorismo.

-ZAPATERO: Nunca. Jamás.

-RAJOY: Usted usó el 11-M.

-ZAPATERO: Nunca. Jamás.

-RAJOY: Usted apoyó lo que ocurrió en el 11-M.

-ZAPATERO: Nunca. Jamás (D2).

La utilización más productiva de las frases interrogativas en este contexto es aquélla que tiene un uso interaccional, concretamente argumentativo y polémico, aunque lo normal sea cuando el emisor solicita información a su interlocutor. Las más empleadas aquí buscan interpelar al contrincante político, exigiéndole o pidiéndole una respuesta. Así lo hizo Rajoy, especialmente en el primer debate, en el que iniciaba el turno de palabra. Este hecho le permitió interrogar a Zapatero y cuestionar las diversas políticas llevadas a cabo en estos cuatro años. Entonces utilizó las frases interrogativas en 63 ocasiones, frente a las 21 de Zapatero. En el segundo debate, en el que Rodríguez Zapatero era quien empezaba, utilizó las frases interrogativas 20 veces frente a las 16 de Rajoy. Como vemos, no fue tan insistente en esta táctica, porque se centró más en las políticas de futuro y criticó con contundencia la labor de Rajoy, tanto en el gobierno como en la oposición, sin plantearle preguntas al respecto.

Encontramos claros ejemplos en el debate del 25 de febrero en los que Rajoy encadena varias preguntas, poniendo en duda la credibilidad de las políticas llevadas a cabo por el presidente:

¿A ustedes qué les parece? ¿Estamos mejor que hace cuatro años? [...]. ¿Cómo se puede decir que España está muy bien? ¿En qué otras materias de las verdaderamente importantes estamos bien? ¿En vivienda? ¿En educación? [...]. ¿En inmigración? [...] ¿En seguridad? [...] ¿Qué es lo que ha hecho el señor Zapatero a lo largo de estos cuatro años, además de discutir la nación y entretenerse con la Alianza de Civilizaciones, la memoria histórica u otras cuestiones? (D1-R).

En el caso del actual presidente, nos encontramos un fragmento cargado también de preguntas dirigidas a Rajoy, en las que hace un repaso por las políticas que los populares han llevado a cabo, poniendo en evidencia de este modo las críticas efectuadas por el propio Rajoy contra Zapatero:

¿Sabe cuántas viviendas protegidas construían en el último año de su mandato? [...] ¿Y sabe cuántas se inician ahora? [...] ¿Cuántas ayudas hacían ustedes a los jóvenes para el alquiler de vivienda? [...] ¿Sabe que hemos multiplicado por tres el gasto en I+D+i? [...] ¿Sabe que hay 40.000 investigadores más en España que cuando ustedes gobernaban? ¿Sabe que somos el segundo país de Europa que más aumenta en patentes? ¿Sabe que en Internet, cuando llegamos al gobierno, solo disponían de acceso uno de cada diez ciudadanos y ahora son cinco de cada diez? (D1-Z). 
Retórica política en los debates televisados: caso de Zapatero-Rajoy (2008)

\subsection{Carácter polémico: paráfrasis, parodia y ataques ad hominem}

El elemento connotativo es soporte fundamental de la caracterización del discurso político como un discurso polémico, en el sentido de que el signo positivo o negativo de las palabras depende de si el que las utiliza las asume como propias o las rechaza como pertenecientes a los otros. Esta dimensión deja marcas, más o menos explícitas, en el discurso; tales marcas son numerosas y de índole diversa.

En los dos debates, se ha utilizado frecuentemente la paráfrasis para criticar las políticas llevadas a cabo por el propio Zapatero o por el gobierno del Partido Popular, incidiendo especialmente en los diversos ministerios ocupados por Rajoy. En el primer debate Rajoy utiliza la paráfrasis en 27 ocasiones, frente a las 24 de Zapatero. En el debate del 3 de marzo, Zapatero hace uso de la paráfrasis en 13 ocasiones y Rajoy, en 16. En el caso de primer debate, podríamos afirmar que es como una "especie de partido de tenis", pues los dos candidatos se recriminan constantemente las políticas que han llevado a cabo en sus años de gobierno. Por ello, en el primer debate, los dos candidatos están más centrados en el pasado que en el futuro, aportando mínimas propuestas sobre sus programas electorales. Veamos algunos ejemplos de ambos debates, comparando las declaraciones de ambos candidatos:

Hemos subido el salario mínimo para defender a la gente de la calle, porque cuando gobernaban permitieron lo que fue la vergüenza del redondeo con el euro, no hicieron nada; las cosas que valían cien pesetas pasaron a valer un euro (D1-Z).

Hay más becarios en el año 1999, cuando yo era ministro, que en el año 2007, en becarios universitarios y en el resto del modelo educativo [...]. Antes le di los datos de las personas que entraron en España en 2005, 2006 y 2007. Ahora le voy a dar los datos de su Gobierno [...], en junio de 2004 había en España 1.776 .000 personas con permiso de residencia. En diciembre de 2007 hay 3,9 millones, es decir mucho más del doble (D1-R).

En lo tocante a la parodia, el emisor introduce el discurso de su adversario para ridiculizarlo. En ese caso, la "reproducción" de las declaraciones del adversario muestra tintes irónicos. Este recurso también se ha utilizado con frecuencia en los dos debates. Rajoy lo empleó 16 veces en el primer debate, frente a las 11 de Zapatero. En el debate del 3 de marzo, más serio y con más propuestas de futuro, su uso bajó considerablemente, empleándose cuatro veces por Zapatero y cinco por Rajoy. Éste emplea la parodia en diversas ocasiones para ridiculizar a su oponente y criticar sus actuaciones:

¿Estamos mejor que hace cuatro años? Depende de a quién le hagamos la pregunta: si se la hacemos a Zapatero nos dirá que estamos en el mejor de los mundos [...]. ¿Qué es lo que ha hecho el señor Zapatero a lo largo de estos cuatro años, además de discutir la nación y entretenerse con la Alianza de Civilizaciones, la memoria histórica u otras cuestiones? (D1-R). 
Lleva una temporada diciendo que soy el peor ministro de la democracia [...]. Seguramente usted es el mejor presidente del Gobierno de la Historia de España desde los Reyes Católicos (D1-R).

Analizaremos, a continuación, algunas parodias empleadas por Zapatero en los dos debates:

¡Pero si usted no se ha preocupado por la economía en cuatro años! ¡Si hemos tenido tres debates sobre el Estado de la Nación y en sus discursos, que son largos, sólo ha dedicado una media de tres minutos a la economía! (D1-Z).

Esto sí que va a ser exclusiva mundial, señor Rajoy... ¡jecir que yo apoyaba la guerra de Irak después de las decisiones que hemos adoptado! (D2-Z).

Los ataques ad hominem se producen cuando el rechazo a las declaraciones del adversario se vuelve muy agresivo y abusa de las descalificaciones, pues afrenta no a las ideas, sino a la persona en sí. Estos ataques personales se han producido también en los dos debates. En el primero de ellos, Rajoy criticó de esta forma al presidente en doce ocasiones, frente a las siete de Zapatero. En el debate segundo, las cosas estuvieron más calmadas en las críticas personales, siendo empleadas dos veces por Zapatero y cuatro por Rajoy.

Zapatero inicia su participación en el primer debate con una fuerte crítica a Rajoy, mostrando de este modo la línea que seguirá el resto del debate.

El principal obstáculo ha sido una oposición que desde el primer día no aceptó el resultado electoral, que ha practicado el insulto personal. Usted mismo, señor Rajoy, que es una barrera que no se puede traspasar en democracia. Que ha crispado, que ha enfrentado a ciudadanos de unas comunidades con otras, que se ha movido entre la mentira y la exageración, que no ha dado respaldo al Gobierno en ninguna de las grandes cuestiones de Estado (D1-Z).

Veremos a continuación algunas críticas dirigidas por Rajoy a Zapatero, acusaciones personales contra el candidato socialista y sus actuaciones siendo presidente del gobierno:

¿Sabe quién es usted, señor Rodríguez Zapatero? Es un señor que con una mano predica el entendimiento y con la otra mano prohíbe a los demás que nos den los buenos días y para colmo me echa la culpa de todo. Usted es el que ha sembrado la discordia, es el que ha querido pactar con los radicales, que el PP no tuviera la más mínima oportunidad de llegar a un entendimiento. [...].Usted es el que ha querido pactar con partidos radicales y extremistas (D1-R).

Usted ha mentido. Porque usted miente siempre, usted no dice la verdad nunca (D2$\mathrm{R})$. 
Retórica política en los debates televisados: caso de Zapatero-Rajoy (2008)

\section{CONCLUSIONES Y REFLEXIONES GENERALES}

Podemos sostener, a grandes rasgos, que el primer debate fue más agresivo, con incidencia de reproches constantes a políticas pasadas, planteándose pocas propuestas de futuro. Asimismo, fue un debate interrogativo, donde ambos se cuestionaban sobre las diversas actuaciones llevadas a cabo en sus respectivas etapas de gobierno.

Rajoy recurrió más veces a las frases interrogativas que Rodríguez Zapatero, a fin de cuestionarle la productividad de sus cuatro años de presidente (63 veces en el primer debate frente a las 21 veces que las usó Zapatero). En el primer debate también se percibieron más paráfrasis, parodias y argumentos ad hominem, fruto de los reproches entre ambos candidatos (58 veces usó Rajoy este tipo de construcciones frente a las 42 de Zapatero).

El primer debate, al ser más vehemente, tuvo una mayor carga retórica que el segundo; en este se repitieron con insistencia varios datos e ideas y se miró más al futuro que al pasado, aunque también hay referencias explícitas y contundentes a las políticas desarrolladas con anterioridad por ambos partidos.

En suma, estas transcripciones reflejan hasta qué punto Rodríguez Zapatero reincidió en los puntos idealistas que aparecieron resumidos en la conclusión del primer debate: igualdad de géneros en el campo laboral y social; lucha contra el paro y el desempleo; defensa de la diversidad y tolerancia cultural; desaprobación de las "guerras ilegales" y apuesta por la paz interna. La repetición de estos tópicos no fue pasajera: el uso de esas frases (muchas veces englobadas en "clichés") le aseguraron un cariz "progresista", "moderno" y abierto a los cambios. Definitivamente, esto colocó a Rodríguez Zapatero en una posición apreciable, en comparación a su contendiente, lo que sutilmente hacía aparecer a este como un antípoda reaccionario.

Con respecto a los contenidos discursivos, es curioso comprobar cómo en la vida cotidiana se da entre nosotros, en términos generales, la doble moral (por llamarlo de alguna manera) de exigir que resplandezca la honradez, pero al mismo tiempo consentir que anuncios o comportamientos comerciales traicionen la confianza del consumidor, sin que se produzca la rebelión de este, aun sabiendo el engaño de que es víctima. Algo semejante ocurre en el terreno político.

Esperamos la máxima transparencia, entrega y sinceridad de nuestros políticos y la honestidad es una de las virtudes más apreciadas. Pues bien, pese a todo sabemos que la corrupción nos circunda y que los políticos pueden mentir, exagerar intencionadamente o lanzar promesas imposibles sin que ninguno de ellos se reprima lo más mínimo por vergüenza propia o miramientos ajenos. Pero es que tampoco el ciudadano dejará de votar por lo general a quien manifiestamente incumple este código, ni se sentirá traicionado por los más recalcitrantes transgresores del código de la honradez 
pública ${ }^{7}$. Tal vez en otros países son más rigurosos y exigentes con las palabras y comportamientos de los políticos, se hallen en el poder o en la oposición. Pero no estamos seguros de ello.

En los debates que estamos comentando era difícil que los espectadores apreciaran la verdad de todas las palabras, dada la endiablada velocidad con que se deslizaban en sus oídos y el carácter técnico de muchas afirmaciones que se realizaban, pero a posteriori hay que concluir que alguno de los contendientes (si no los dos) mentía o exageraba. No solamente porque las acusaciones de ese signo se repetían machaconamente (véase alguno de los fragmentos que han quedado consignados anteriormente), sino porque los comentarios periodísticos lo han puesto de manifiesto y porque es metafísicamente imposible que dos personas estén ofreciendo visiones contrapuestas y sean plausibles en ambos casos. Porque no se trataba de opiniones, sino de hechos.

Ya sabemos que los datos estadísticos pueden ser interpretados de distinta manera, según sean ofrecidos, y también sacar conclusiones de una cifra total o de una parte, con lo que cambia la perspectiva que se ofrece. Nosotros hemos puesto de manifiesto el aprovechamiento de las posibilidades lingüísticas y retóricas para los fines que los candidatos pretenden, pero nos queda la frustración de no poder entrar a señalar mentiras, exageraciones o desviaciones que son lo que más directa y arteramente traicionan la confianza que los espectadores y electores han puesto en ellos. No llegamos tan lejos, pero nos consuela pensar que el análisis retórico cumple "una función defensiva contra las insidias de la persuasión oculta” (Mortara, 1991: 11). ¿Las detectarán los ciudadanos?

\section{REFERENCIAS BIBLIOGRÁFICAS}

ALVAR, M.: "Lenguaje político: el debate sobre el Estado de la Nación", Lingüística española actual, n XIII/1 (1991), pp. 5-46.

ARMAÑANZAS, E.; y DÍAZ NOCl, J. (1996): Periodismo y argumentación. Bilbao: Universidad del País Vasco.

BERRIO, J. (1983): Teoría social de la persuasión. Barcelona: Mitre.

BERROCAL, S.: "Una aproximación a la nueva retórica del líder político televisivo", Doxa, n 2 (2002), pp. 53-67.

CANTAVELLA, J. et álii.: "Algunos aspectos lingüísticos de los debates electorales Zapatero-Rajoy 2008", Estudios sobre el Mensaje Periodístico, no 14 (2008), pp. 79-98.

CANTAVELLA, J.; y SERRANO, J. (coords.) (2007): Redacción para periodistas: opinar y argumentar. Madrid: Universitas.

\footnotetext{
${ }^{7}$ Como nos decía uno de ellos, en muestra de una actitud que no sabemos si calificar de sincera o de cínica, "las promesas electorales están para no ser cumplidas" (Juan Cantavella: Entrevista a Ramón Tamames, en Diario de Cádiz, 1 de junio de 1991). Véase al respecto el artículo del teólogo Hans Kung: "Está justificada la mentira en política?", en el diario El País, 15 de mayo de 2008, pp. 37-38.
} 
Retórica política en los debates televisados:

caso de Zapatero-Rajoy (2008)

DUBOIS, J. et álii. (1979): Diccionario de lingüística. Madrid: Alianza Editorial.

FERNÁNDEZ, M. (1999): La lengua de la comunicación política (2 vols.). Madrid: Arco Libros.

HERRERO, C. (1996): Periodismo político y persuasión. Madrid: Actas.

MORALES, O. et álii. (2006): "La argumentación en la propaganda política de la campaña de las elecciones venezolanas de 2005", Revista Latina de Comunicación Social [en línea <http://www.ull.es/publicaciones/latina/200619Morales_y Marín.htm>. Consulta: 25 abril 2008].

MORTARA GARAVELLI, B. (1991): Manual de retórica. Madrid: Cátedra.

MUCCHIELLI, A. (2002): El arte de influir. Madrid: Cátedra.

MUÑOZ ALONSO, A. et álli. (1995): Comunicación política. Madrid: Universitas.

NIETO, R. (2000): Lenguaje y política. Madrid: Acento Editorial.

NÚÑEZ CABEZAS, E.; y GUERRERO SALAZAR, S. (2002): El lenguaje político español. Madrid: Cátedra.

NÚÑEZ LADEVĖZE, L.: "Lenguaje del político, lenguaje del informador", Estudios sobre el Mensaje Periodístico, no 5 (1999), pp. 11-127.

PERELMAN, C.; y OLBRECHTS-TYTECA, L. (1989): Tratado de la argumentación. Madrid: Gredos.

SANTAMARÍA, L.; y CASALS, M. J. (2000): La opinión periodística. Argumentos y géneros para la persuasión. Madrid: Fragua.

WESTON, A. (1994): Las claves de la argumentación. Barcelona: Ariel.

\section{Breve semblanza biográfica de los autores}

Juan Cantavella Blasco es Catedrático de Periodismo en la Universidad CEU San Pablo (Madrid), a cuya Comisión de Doctorado pertenece en representación de la Facultad de Humanidades y Ciencias de la Comunicación. Dirige un proyecto de investigación y ha impartido cursos en la Universidad de La Habana (Cuba), Autónoma de Nuevo León (Monterrey. México) y San Martín de Porres (Lima. Perú).

César Mejía Chiang es doctor y magíster en Periodismo, profesor de Historia e investigador de la Facultad de Ciencias de la Comunicación, Turismo y Psicología de la Universidad de San Martín de Porres (Lima-Perú). Su tesis doctoral (2010), en la Universidad CEU San Pablo de Madrid, versa sobre la composición de los géneros interpretativos en la prensa generalista.

(Recibido el 04-06-2009, aceptado el 24-03-2010) 